\title{
Radiation
}

ISSN 0909-0495

Editor: G. Ice

\section{Chalcone JAI-51 improves efficacy of synchrotron microbeam radiation therapy of brain tumors}

\author{
Audrey Bouchet, Ahcene Boumendjel, Enam Khalil, Raphael Serduc, Elke \\ Bräuer, Erik Albert Siegbahn, Jean A. Laissue and Jean Boutonnat
}

J. Synchrotron Rad. (2012). 19, 478-482

Copyright (C) International Union of Crystallography

Author(s) of this paper may load this reprint on their own web site or institutional repository provided that this cover page is retained. Republication of this article or its storage in electronic databases other than as specified above is not permitted without prior permission in writing from the IUCr.

For further information see http://journals.iucr.org/services/authorrights.html

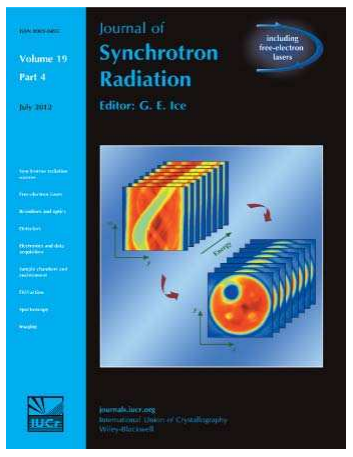

Synchrotron radiation research is rapidly expanding with many new sources of radiation being created globally. Synchrotron radiation plays a leading role in pure science and in emerging technologies. The Journal of Synchrotron Radiation provides comprehensive coverage of the entire field of synchrotron radiation research including instrumentation, theory, computing and scientific applications in areas such as biology, nanoscience and materials science. Rapid publication ensures an up-to-date information resource for scientists and engineers in the field.

Crystallography Journals Online is available from journals.iucr.org 
Journal of

Synchrotron

Radiation

ISSN 0909-0495

Received 20 February 2012

Accepted 5 April 2012

\section{Chalcone JAI-51 improves efficacy of synchrotron microbeam radiation therapy of brain tumors}

\author{
Audrey Bouchet, ${ }^{\mathrm{a}, \mathrm{b}, \mathrm{c}}$ Ahcene Boumendjel, ${ }^{\mathrm{d}}$ Enam Khalil, ${ }^{\mathrm{e}}$ Raphael Serduc, ${ }^{\mathrm{a}, \mathrm{b}}$ * \\ Elke Bräuer, ${ }^{c}$ Erik Albert Siegbahn, ${ }^{f}$ Jean A. Laissue ${ }^{g}$ and Jean Boutonnat ${ }^{\text {h }}$ \\ aINSERM, U836, F-38043 Grenoble, France, ${ }^{\mathbf{b}}$ Grenoble Institut des Neurosciences, Université \\ Joseph Fourier, UMR-S836, F-38043 Grenoble, France, ${ }^{\mathbf{c} E u r o p e a n ~ S y n c h r o t r o n ~ R a d i a t i o n ~ F a c i l i t y, ~}$ \\ F38043 Grenoble, France, 'CNRS, UMR 5063, Bâtiment E, Pôle Chimie, F-38700 Grenoble, \\ France, ${ }^{\mathbf{e}}$ Faculty of Pharmacy, University of Jordan, Amman, Jordan, 'Department of Physics P8:02, \\ Stockholm University, S-17176 Stockholm, Sweden, ${ }^{\mathrm{g}}$ Institute of Pathology, University of Bern, \\ $\mathrm{CH}-3010$ Bern, Switzerland, and ${ }^{\mathbf{h}}$ Département d'Anatomie et Cytologie Pathologiques (DACP), \\ UJF, UMR_S1036 BCI, CHU, Hôpital Michallon, Grenoble, F-38000, France. \\ E-mail: raph.serduc@gmail.com
}

Microbeam radiation therapy (MRT), a preclinical form of radiosurgery, uses spatially fractionated micrometre-wide synchrotron-generated X-ray beams. As MRT alone is predominantly palliative for animal tumors, the effects of the combination of MRT and a newly synthesized chemotherapeutic agent JAI-51 on 9L gliosarcomas have been evaluated. Fourteen days (D14) after implantation (D0), intracerebral 9LGS-bearing rats received either MRT, JAI-51 or both treatments. JAI-51, alone or immediately after MRT, was administered three times per week. Animals were kept up to $\sim 20$ weeks after irradiation or sacrificed at D16 or D28 after treatment for cell cycle analysis. MRT plus JAI-51 increased significantly the lifespan compared with MRT alone $(p=0.0367)$. JAI-51 treatment alone had no effect on rat survival. MRT alone or associated with JAI-51 induced a cell cycle blockade in $\mathrm{G} 2 / \mathrm{M}(p<0.01)$ while the combined treatment also reduced the proportion of G0/G1 cells. At D28 after irradiation, MRT and MRT/JAI-51 had a smaller cell blockade effect in the $\mathrm{G} 2 / \mathrm{M}$ phase owing to a significant increase in tumor cell death rate $(<2 \mathrm{c})$ and a proportional increase of endoreplicative cells $(>8 \mathrm{c})$. The combination of MRT and JAI-51 increases the survival of 9LGS-bearing rats by inducing endoreduplication of DNA and tumor cell death; further, it slowed the onset of tumor growth resumption two weeks after treatment.

(C) 2012 International Union of Crystallography Printed in Singapore - all rights reserved

\section{Introduction}

Microbeam radiation therapy (MRT) is an alternative form of brain tumor radiosurgery which is being developed worldwide, to a large extent at the European Synchrotron Radiation Facility (France) (Slatkin et al., 1992). It uses synchrotrongenerated X-rays spatially fractionated into lattices of quasiparallel microbeams (tens of micrometres wide, hundreds of micrometres spaced on-centre) (Slatkin et al., 1994, 1995). Orthogonal crossfired irradiations performed on a 9L gliosarcoma (9LGS) model implanted in rat brains showed that MRT increases significantly the median survival times of irradiated animals without severely impairing unidirectionally irradiated ipsilateral or contralateral brain tissues (Serduc et al., 2008; Smilowitz et al., 2006; Dilmanian et al., 2002; Laissue et al., 1998). Tumor control might be related to a preferential effect of MRT on tumor vessels: first evidence has recently been given in vivo (Bouchet et al., 2010); recent experimental data showed a significant decrease in tumor blood volume after MRT, associated with an $80 \%$ tumor control rate (Bouchet et al., 2010). However, despite the high radiation doses used (Serduc, Bouchet et al., 2009; Serduc, BräuerKrisch et al., 2009; Bouchet et al., 2010), radio-resistant 9LGS (Kim et al., 1999) was not totally sterilized and some tumor cells located at the tumor margins kept proliferating [Ki67 positive labelling (Bouchet et al., 2010; Serduc, Bouchet et al., 2009)].

Clinical brain tumor treatment is often based on chemotherapy and radiotherapy (Stupp et al., 2005; Stupp \& Roila, 2008). Chemotherapy, adjuvant to radiotherapy, contributes to tumor control by decreasing mitotic activity of and infiltration by surviving tumor cells (Bauman et al., 1999), but the median overall lifespan of glioblastoma-bearing patients has only increased by 2.5 months in the course of the last 30 years. 
Recent clinical trials have used bevacizumab and irinotecan on recurrent malignant glioma; toxicity was acceptable, but the treatment resulted in only $38 \%$ probability for six months progression-free survival (Vredenburgh, Desjardins, Herndon, Dowell et al., 2007; Vredenburgh, Desjardins, Herndon, Marcello et al., 2007). Currently, there is no other regimen for glioblastoma treatment than the Stupp protocol (Stupp et al., 2005), which ends up with a low benefit in terms of overall survival. Some studies have described the antimitotic potential of flavonoid derivatives and their capacity to reverse multidrug resistance (Jeong et al., 2007; NakagawaGoto et al., 2010; Duraj et al., 2005). Therefore, we have used a new chalcone (JAI-51) for the present study, a microtubule polymerization inhibitor that we have recently developed; JAI-51 has shown promising results on glioma models in vitro (Boumendjel et al., 2008) and in vivo (rodents) (Boumendjel et al., 2009). Chalcones that are flavone precursors have been investigated for their antiproliferative effect; flavonoids are polyphenols present in fruits, vegetables and many other comestibles. Colchicines, vinca alkaloids and taxanes are among many other natural substances that affect microtubular dynamics (Boumendjel et al., 2008).

In this work we have evaluated for the first time the association of MRT with JAI-51 for the treatment of 9LGS implanted in rat brains, particularly the effects on the median survival time of those rats. Further, we have characterized the effect of both treatments, alone or combined, on the tumor cell cycle ex vivo.

\section{Materials and methods}

All operative procedures related to animal care strictly conformed to the guidelines of the French Government (licenses 380324/380456 and A3818510002); they were reviewed by the Internal Evaluation Committee for Animal Welfare of the ESRF. The anesthetic procedure used in this study was isoflurane $(5 \%$ in air) for induction and an i.p. injection of xylazine/ketamine $\left(64.5 / 5.4 \mathrm{mg} \mathrm{kg}^{-1}\right)$ for maintenance.

\subsection{Tumor implantation}

Ninety-four anesthetized male Fisher 344 rats were implanted with $10^{4}$ 9LGS cells in the right caudate nucleus as described elsewhere (Serduc, Bräuer-Krisch et al., 2009). Animals bearing 9L gliosarcoma were randomly divided into four groups: untreated controls ['Control' $(n=26)$ ], rats subjected to chemotherapy alone ['JAI-51' $(n=15)]$, rats given MRT 14 days after tumor implantation ['MRT' $(n=26)$ ], rats with MRT plus chemotherapy ['MRT/JAI-51' $(n=27)$ ]. Thirty-two rats were then culled at day 16 (D16) or D28 after treatment for cytometry studies $(n=32)$ and the others kept for survival analysis $(n=62)$.

\subsection{Chemotherapy}

The chalcone derivate JAI-51 was obtained by the condensation of $2^{\prime}, 4^{\prime}, 6^{\prime}$-trimethoxyacetophenone with 1- methylindolyl-3-carboxaldehyde in the presence of $\mathrm{KOH}$ in a mixture of water and methanol. Freshly prepared aqueous JAI-51 solution $(48 \mu \mathrm{L}$ JAI-51 stock solution $2 M+192 \mu \mathrm{L}$ DMSO + $11.8 \mathrm{ml}$ PBS) was administered to animals through i.p. injections $\left(5.0 \mathrm{ml} \mathrm{kg}^{-1}\right.$ body weight) three times weekly with intervals of two days for four weeks. Chemotherapy (combined or not with radiation treatment) started 14 days after implantation, i.e. at the same day as MRT (D0).

\subsection{Microbeam radiation therapy}

Brain tumor irradiations were performed at the European Synchrotron Radiation Facility (ID17) as described previously (Serduc, Bouchet et al., 2009). The X-ray spectrum extended from approximately 50 to $350 \mathrm{keV}$ (median energy around $90 \mathrm{keV}$ ). The dose rate was $\sim 16000 \mathrm{~Gy} \mathrm{~s}^{-1}$. The beam was spatially fractionated into a $1 \mathrm{~cm}$-wide array of microbeams by using a multi-slit collimator (Bräuer-Krisch, Requardt et al., 2009). Two orthogonal arrays were used, each composed of 50 $14 \mathrm{~mm}$-high $50 \mu \mathrm{m}$-wide microbeams spaced $200 \mu \mathrm{m}$ oncentre. The in-beam skin entrance dose was $480 \mathrm{~Gy}$. Animal immobility during exposure was checked on three control video screens. The whole irradiation procedure lasted $<2 \mathrm{~min}$.

\subsection{Dosimetry}

The spatial configuration of the microbeams (width and spacing) was checked microscopically in radiochromic films (Gafchromic, HD-810) (Crosbie et al., 2008) to ensure the correct alignment of the multi-slit collimator and thus the homogeneity of the dose distribution. No experimental dosimetry studies were performed. Monte Carlo dose computations, using a rat-head phantom (Siegbahn et al., 2006) for this irradiation geometry, were carried out for a unique microbeam array (Fig. 1).

\subsection{Survival analysis}

The time between implantation and death was recorded as the survival time; one day was added in cases of euthanasia. Kaplan Meier survival data were plotted versus time after tumor implantation. The survival curves were compared using a log rank test in Prism (GraphPad Software, San Diego, USA).

\subsection{Cytometry}

Blood cells were counted in a Beckman apparatus in control $(n=6), \mathrm{JAI}-51(n=5)$, MRT $(n=14)$ and MRT/JAI-51 $(n=7)$ treated animals. At D16 and D28 after implantation the brains were excised and cut at the tumor injection site by means of a pre-cooled Kopf matrix (David Kopf Instruments, USA). $1 \mathrm{~mm}^{3}$ tumor specimens were taken and used to make imprints on glass slides and air dried. DNA content was measured in 200 tumor cells per sample under a microscope (Zeiss, Germany) at the absorption maximum for the Feulgen stain, $546 \mathrm{~nm}$, in areas chosen at random. Calibration was performed with human lymphocytes and normal glial cells as internal reference to define the normal diploid (2c) value. These measurements assess the DNA distribution pattern of the 
tumor cell population. The ploidy of the 9L cell line which was used for injection was controlled by flow cytometry. The average DNA content in the G0/G1 phase of the 9LGS cell line was $\sim 3.5 \mathrm{c}$. The same data were found cytometrically on Feulgen-stained slides: the first peak in DNA content, corresponding to the G0/G1 phases, was between $3 \mathrm{c}$ and $4 \mathrm{c}$, and for G2/M between 6.5 and 7.5c. Cells with DNA content between $4 \mathrm{c}$ and $6.5 \mathrm{c}$ were assigned to the $\mathrm{S}$ phase. Cells with DNA contents lower than those of G0/G1 cells displayed the morphology of apoptotic/necrotic cells. Cells with DNA contents $>7.5 \mathrm{c}$ were considered as cells that underwent endoreduplication. For each group, the mean \pm one standard deviation (SD) was calculated for the cell population in each phase and presented in Fig. 3. Statistical analyses were performed using the GraphPad Prism program; a two-way ANOVA test was used (Bonferroni post-tests). Values were considered significantly different when $p<0.05$.

\section{Results}

\subsection{Dosimetry}

The dose profile for a single array of the microbeam is plotted in Fig. 1. The peak dose, deposited at a depth of $1 \mathrm{~cm}$ in rat brain, was $418 \mathrm{~Gy}$, and generated a valley dose of 18.6 Gy (peak-to-valley dose ratio $\simeq 22.4$ ).

\subsection{Survival}

Fig. 2 shows that rats in the control and the JAI-51 group survived for a short time, $19( \pm 1.5)$ and $18( \pm 1.8)$ days after tumor inoculation, respectively. MRT significantly increased the median survival time (MST) of irradiated rats $(186 \%, p<$ 0.001). When both treatments were applied, a significant increase in lifespan was found between the MRT (MST of 35.5 days) and MRT/JAI-51 groups [MST of 48 days after implantation, 252\% $(p<0.001)$ and $135 \%(p=0.0367)$ compared with the control and MRT groups, respectively].

\subsection{Cytometry}

Fig. 3 shows the repartition of the cells in the different phases of the cell cycle at D16 and D28. At D16 there was no difference in phase distribution between the control and JAI-

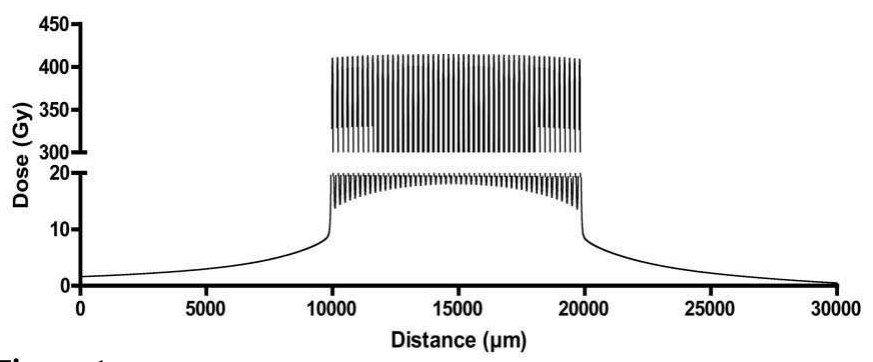

Figure 1

Calculated dose profile for a single microbeam array of a $10 \mathrm{~mm} \times 14 \mathrm{~mm}$ irradiation field. The peak-to-valley dose ratio calculated at a depth of $1 \mathrm{~cm}$ in a rat head is 22.4 , resulting in a maximum valley dose of $18.6 \mathrm{~Gy}$. The in-microbeam entrance dose was $480 \mathrm{~Gy}$, delivering a 418 Gy peak dose at $1 \mathrm{~cm}$ depth.

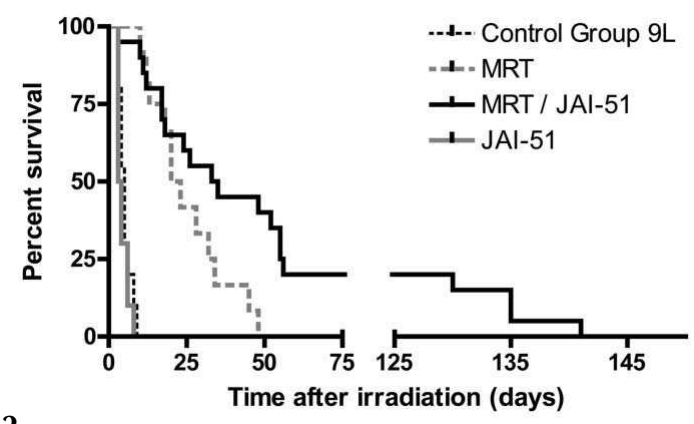

Figure 2

Survival curves of rats bearing intracerebral 9LGS (grey), treated by JAI51 (dashed black), irradiated by MRT (dashed grey) or treated by MRT and JAI-51 (solid black). MRT and/or JAI-51 were performed at day 14 after tumor implantation.

51 groups. MRT induced a significant arrest in the $\mathrm{G} 2 / \mathrm{M}$ phase $(p<0.001)$ and a decrease in the $\mathrm{G} 0 / \mathrm{G} 1$ population $(p<0.01)$. In the MRT/JAI-51 group, G2/M and G0/G1 populations were significantly higher and lower, respectively, than those found in the control group $(p<0.001)$. A significant difference was found in the G0/G1 population between MRT/JAI-51 and MRT groups $(-20.5 \%, p<0.05)$.

At D28, MRT irradiated tumors exhibited the same cell cycle profile as the unirradiated control group $(p>0.05$ for each population). The G0/G1 cell population was found to be higher in the MRT group than in the MRT/JAI-51 group $(p<$ $0.05)$. This may be due to the increases in the $<2.5 \mathrm{c}$ and $>8 \mathrm{c}$ population in the MRT/JAI-51 at D28. The hyperploidy values obtained for the different groups were compared with those of the control group. Only the hyperploidy in the MRT/JAI-51 at D28 was significantly higher than the control value ( $p=$ $0.0007)$.

\subsection{Blood cell counts}

The total blood cell counts carried out at D16 and D28 are shown in Table 1. None of the blood count values in the MRT/ JAI-51 group showed significant differences from the control

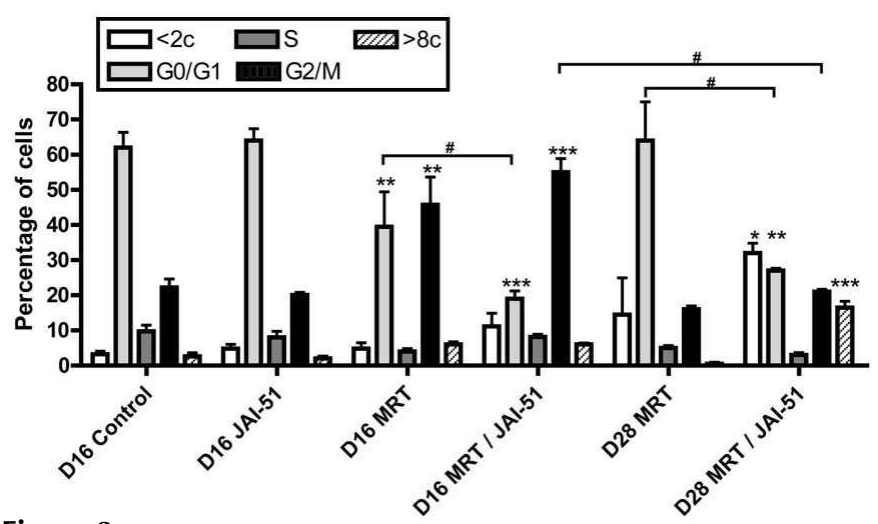

Figure 3

Histograms showing the cycle distribution in control 9LGS, MRT and/or JAI-51 treated tumors at D16 and D28, i.e. two days and 14 days after treatment start. Each treatment started at day 14 after implantation. The different cell cycle phases, G0/G1, S, G2/M, endoreduplicative and apoptotic/necrotic cells are represented in light grey, dark grey, black, white and hashed histograms, respectively. $*, * *, * * *: p<0.05,0.01,0.001$, significantly different from control (similar cell cycle stage). \# $p<0.05$. 
Table 1

Number of red blood cells (RBC), white blood cells (WBC) and thrombocytes ( \pm SD) counted in blood samples from rats having received either MRT, JAI-51 or both treatments.

Cell counts were performed 2 and 14 days after treatment starts (D16 and D28). The symbol $(*)$ indicates significant difference from the control $(p=0.02)$. $\mathrm{T} 1^{-1}=$ trillion per litre.

\begin{tabular}{lllllll}
\hline & \multicolumn{1}{l}{ Day 16} & & & \multicolumn{2}{c}{ Day 28 } \\
\cline { 2 - 4 } \cline { 6 - 7 } Blood content & Control & JAI-52 & MRT & MRT/JAI-52 & MRT/JAI-52 & MRT \\
\hline WBC $\left(\mathrm{g} \mathrm{l}^{-1}\right)$ & $3.3( \pm 1.7)$ & $5.9( \pm 2.9)$ & $2.2( \pm 2.2)$ & $2.3( \pm 1.2)$ & $7.0( \pm 1)$ \\
RBC $\left(\mathrm{T} \mathrm{l}^{-1}\right)$ & $7.7( \pm 1.5)$ & $8.0( \pm 0.5)$ & $7.5( \pm 0.7)$ & $7.6( \pm 1.1$ & $8.0( \pm 1)$ \\
Thrombocytes $\left(\mathrm{g} \mathrm{l}^{-1}\right)$ & $611( \pm 202)$ & $212( \pm 174)^{*}$ & $568( \pm 14)$ & $488( \pm 302)$ & $716( \pm 291)$ & $\left.8.0( \pm 1)^{*}\right)$ \\
\hline
\end{tabular}

group. JAI-51 induced a significant decrease in thrombocyte number at D16 after treatment. The white blood cells count in the MRT group at D28 was significantly higher than that measured in the control group $(p=0.02)$.

\section{Discussion}

We have investigated the relevance of the association between a chalcone called JAI-51, inhibitor of tubulin polymerization, and MRT, on intracerebral 9LGS in rats. Our results showed that JAI-51 alone does not act on this tumor, but that it may be effective if a radiation treatment is given prior to its administration. Indeed, the MST of MRT-treated animals increased significantly when MRT was associated with JAI-51 treatment $(p=0.0367)$. The increase in lifespan was associated with a significant increase in the proportion of cells blocked in $G 2 / M$, as well as in proportions of endoreplicative ( $>8 \mathrm{c}$ peak) and pyknotic/apoptotic cells (sub-G0/G1 peak) two days after the start of the treatments.

All MRT studies performed on implanted brain tumors in rodents showed significant increases in lifespan of irradiated animals [e.g. $186 \%$ versus unirradiated controls, $p<0.001$ (Laissue et al., 1998; Serduc, Bouchet et al., 2009; Serduc, Bräuer-Krisch et al., 2009; Serduc et al., 2008; Bouchet et al., 2010)], in association with limited histological damage of irradiated normal brain tissues (for a review, see BräuerKrisch, Serduc et al., 2009). However, some previous works revealed that a small percentage of brain tumor cells, $2 \%$ according to Dilmanian et al. (2002), kept their proliferative activity after 'effective' MRT. More recent experiments confirmed this hypothesis: Ki67 positive tumor cells were found at the 9LGS margins after MRT (Bouchet et al., 2010; Serduc, Bouchet et al., 2009; Serduc, Bräuer-Krisch et al., 2009; Serduc et al., 2008). Here we show for the first time that the tubulin polymerization inhibitor JAI-51 used as adjuvant helps in tumor control after MRT. Conversely, JAI-51 alone had a significant effect on subcutaneously implanted GL26 tumor cells in mice by slowing tumor growth (Boumendjel et al., 2009), but the tumor micro-environments were drastically different between the two models studied. In the GL26 glioma, tumoral blood vessels were fenestrated, while the 9LGS exhibited a weakly disrupted blood-tumor barrier (Bouchet et al., 2010; Lemasson et al., 2010). This factor might have considerably limited the diffusion of the chemo-agent (349 Da) from the blood into the tumor parenchyma; diffusion of JAI-51 into 9LGS probably remained insufficient to have a significant effect on tumor growth and survival. Thus, a major obstacle to the efficiency of chemotherapy for brain tumors may reside in the presence of the blood-brain (and bloodtumor) barrier(s) which limit considerably the diffusion of these molecules into the tumor (van Vulpen et al., 2002). We recently demonstrated that similar MRT protocols (400 Gy, $50 / 200 \mu \mathrm{m}$ ), applied to 9LGS, specifically increased tumor vessel permeability (Bouchet et al., 2010). Our present results confirm that a pre-irradiation of intracerebral 9LGS is required to allow an uptake of JAI-51 that is capable of exerting a significant adjuvant effect.

The increase in MST of rats which received both treatments is therefore likely to be due to the synergistic effect of MRT with JAI-51. It has been shown in vivo that MRT protocols similar to that used in our study induced an increase in tumor blood vessel permeability while no changes were observed in normal brain tissue (Bouchet et al., 2010; Dilmanian et al., 2003; Serduc et al., 2008). The radiation-induced increase in the blood-tumor barrier might thus have allowed a preferential uptake of JAI-51 by the tumor. This hypothesis would be in keeping with the significant difference between the MRT and MRT/JAI-51 groups, in proportions of G0/G1 cells observed on D16. Indeed, MRT induced a significant redistribution of the cell cycle stages of tumor cells: a decreased proportion of tumor cells in the G0/G1 stages $(-20 \%, p<$ 0.05 , compared with the MRT group), as well as a blockade of cells in $\mathrm{G} 2 / \mathrm{M}$ as detected by a slight but non-significant increase of the proportion of $\mathrm{G} 2 / \mathrm{M}$ and $<2 \mathrm{c}$ cells. The longer blockade in G2/M and the accumulation of $<2 \mathrm{c}$ and $>8 \mathrm{c}$ tumor cells slowed tumor growth and explained, at least in part, the prolonged survival obtained in the MRT/JAI-51 group. The biological mechanisms of cell death induced by JAI-51, described elsewhere (Boumendjel et al., 2008, 2009), correlate with the results of our cell cycle study. At D28, the results of cell cycle analysis in the MRT group were similar to those noted in the control group, an indication that the tumor cells that have survived after the irradiation were able to proliferate after a short blockade in G2/M. Cancer cells may use endoreduplication as means of survival during mitotic inhibition; for instance, some mutant cancer cells undergo endoreduplication rather than apoptosis upon treatment with antimitotic drugs such as colcemid and vinblastine (Lee et al., 2009). However, some of these polyploid cancer cells can revert to the mitotic cell cycle by means of a process of genome reduction, 'depolyploidization'. Survival from antimitotic drug effects by endoreduplication and depolyploidi- 
zation may be the strategy of cancer cells aiming to become less sensitive to anti-mitotic drugs (Lee et al., 2009).

In this study we applied the JAI-51 regimen that has been used previously for the human glioblastoma cell line (GL26) implanted in mouse legs (Boumendjel et al., 2009). The MST of the MRT/JAI-51 group might be increased by optimizing drug delivery, especially by the delay between the first injection and MRT, a parameter that might be refined by varying the timing of the first drug injection. Khil et al. (2000) showed that the optimal choice of the time schedule for BCNU adjuvant chemotherapy of the 9LGS tumor was directly linked to significant improvement of the animal survival. Furthermore, the basic geometry chosen for tumor targeting in this study could be improved by use of recent improvements developed at the ESRF. Three-dimensional interlaced or interspersed geometry (Serduc, Bräuer-Krisch et al., 2009; Serduc, BräuerKrisch et al., 2010; Bräuer-Krisch et al., 2005) combined with image-guided irradiation (Serduc, Berruyer et al., 2010) may improve MRT efficiency, mainly by reducing the radiationinduced normal brain tissue damage while delivering a high (uniform) dose to the tumor.

To conclude, we report here for the first time the potential of a chalcone chemotherapy associated with MRT. The adjunction of an antimitotic drug at an optimal time after MRT might help in reducing the radiation dose to achieve an even better sparing of normal tissues.

Enam Khalil contributed to this work during her sabbatical leave which was financially supported by the University of Jordan, Amman, Jordan.

\section{References}

Bauman, G. S., MacDonald, W., Moore, E., Ramsey, D. A., Fisher, B. J., Amberger, V. R. \& Del Maestro, R. M. (1999). J. Neurooncol. 44, 223-231.

Bouchet, A., Lemasson, B., Leduc, G., Maisin, C., Bräuer-Krisch, E., Siegbahn, E. A., Renaud, L., Remy, C., Bravin, A., Laissue, J. A., Barbier, E. \& Serduc, R. (2010). Int. J. Radiat. Oncol. Biol. Phys. 78, 1503-1512.

Boumendjel, A., Boccard, J., Carrupt, P. A., Nicolle, E., Blanc, M., Geze, A., Choisnard, L., Wouessidjewe, D., Matera, E. L. \& Dumontet, C. (2008). J. Med. Chem. 51, 2307-2310.

Boumendjel, A., McLeer-Florin, A., Champelovier, P., Allegro, D., Muhammad, D., Souard, F., Derouazi, M., Peyrot, V., Toussaint, B. \& Boutonnat, J. (2009). BMC Cancer, 9, 242.

Bräuer-Krisch, E., Requardt, H., Brochard, T., Berruyer, G., Renier, M., Laissue, J. A. \& Bravin, A. (2009). Rev. Sci. Instrum. 80, 074301.

Bräuer-Krisch, E., Requardt, H., Regnard, P., Corde, S., Siegbahn, E. A., Leduc, G., Blattmann, H., Laissue, J. \& Bravin, A. (2005). Nucl. Instrum. Methods Phys. Res. A, 548, 69-71.

Bräuer-Krisch, E., Serduc, R., Siegbahn, E. A., Le Duc, G., Prezado, Y., Bravin, A., Blattmann, H. \& Laissue, J. A. (2009). Mutat. Res. 704, 160-166.

Crosbie, J. C., Svalbe, I., Midgley, S. M., Yagi, N., Rogers, P. A. \& Lewis, R. A. (2008). Phys. Med. Biol. 53, 6861-6877.

Dilmanian, F. A., Button, T. M., Le Duc, G., Zhong, N., Peña, L. A., Smith, J. A., Martinez, S. R., Bacarian, T., Tammam, J., Ren, B., Farmer, P. M., Kalef-Ezra, J., Micca, P. L., Nawrocky, M. M., Niederer, J. A., Recksiek, F. P., Fuchs, A. \& Rosen, E. M. (2002). Neuro-oncol, 4, 26-38.

Dilmanian, F. A., Hainfeld, J. F., Kruse, C. A., Cool, C. D., Sze, C. I., Laterra, J. S., Feldman, A., Gatley, S. J., Nawrocky, M. M. \&
Yakupov, R. (2003). NSLS Activity Report 2002, Abstract dilm0599, http://www.bnl.gov/isd/documents/25005/Abstracts/dilm0599.pdf.

Duraj, J., Zazrivcova, K., Bodo, J., Sulikova, M. \& Sedlak, J. (2005). Neoplasma, 52, 273-279.

Jeong, J. M., Choi, C. H., Kang, S. K., Lee, I. H., Lee, J. Y. \& Jung, H. (2007). J. Pharm. Pharm. Sci. 10, 537-546.

Khil, M. S., Kolozsvary, A., Apple, M. \& Kim, J. H. (2000). Int. J. Radiat. Oncol. Biol. Phys. 47, 511-516.

Kim, J. H., Khil, M. S., Kolozsvary, A., Gutierrez, J. A. \& Brown, S. L. (1999). Int. J. Radiat. Oncol. Biol. Phys. 45, 1035-1040.

Laissue, J. A., Geiser, G., Spanne, P. O., Dilmanian, F. A., Gebbers, J. O., Geiser, M., Wu, X. Y., Makar, M. S., Micca, P. L., Nawrocky, M. M., Joel, D. D. \& Slatkin, D. N. (1998). Int. J. Cancer, 78, 654660.

Lee, H. O., Davidson, J. M. \& Duronio, R. J. (2009). Genes Dev. 23, 2461-2477.

Lemasson, B., Serduc, R., Maisin, C., Bouchet, A., Coquery, N., Robert, P., Le Duc, G., Troprès, I., Rémy, C. \& Barbier, E. L. (2010). Radiology, 257, 342-352.

Nakagawa-Goto, K., Chang, P. C., Lai, C. Y., Hung, H. Y., Chen, T. H., Wu, P. C., Zhu, H., Sedykh, A., Bastow, K. F. \& Lee, K. H. (2010). J. Med. Chem. 53, 6699-6705.

Serduc, R., Berruyer, G., Brochard, T., Renier, M. \& Nemoz, C. (2010). J. Synchrotron Rad. 17, 325-331.

Serduc, R., Bouchet, A., Bräuer-Krisch, E., Laissue, J. A., Spiga, J., Sarun, S., Bravin, A., Fonta, C., Renaud, L., Boutonnat, J., Siegbahn, E. A., Estève, F. \& Le Duc, G. (2009). Phys. Med. Biol. 54, 6711-6724.

Serduc, R., Bräuer-Krisch, E., Bouchet, A., Renaud, L., Brochard, T., Bravin, A., Laissue, J. \& Le Duc, G. (2009). J. Synchrotron Rad. 16, 587-590.

Serduc, R., Bräuer-Krisch, E., Siegbahn, E. A., Bouchet, A., Pouyatos, B., Carron, R., Pannetier, N., Renaud, L., Berruyer, G., Nemoz, C., Brochard, T., Remy, C., Barbier, E. L., Bravin, A., Le Duc, G., Depaulis, A., Esteve, F. \& Laissue, J. A. (2010). PLoS One, 5, e9028.

Serduc, R., Christen, T., Laissue, J., Farion, R., Bouchet, A., Sanden, B., Segebarth, C., Bräuer-Krisch, E., Le Duc, G., Bravin, A., Rémy, C. \& Barbier, E. L. (2008). Phys. Med. Biol. 53, 3609-3622.

Siegbahn, E. A., Stepanek, J., Bräuer-Krisch, E. \& Bravin, A. (2006). Med. Phys. 33, 3248-3259.

Slatkin, D. N., Dilmanian, F. A. \& Spanne, P. (1994). US Patent 5339347.

Slatkin, D. N., Spanne, P., Dilmanian, F. A., Gebbers, J. O. \& Laissue, J. A. (1995). Proc. Natl Acad. Sci. USA, 92, 8783-8787.

Slatkin, D. N., Spanne, P., Dilmanian, F. A. \& Sandborg, M. (1992). Med. Phys. 19, 1395-1400.

Smilowitz, H. M., Blattmann, H., Bräuer-Krisch, E., Bravin, A., Di Michiel, M., Gebbers, J. O., Hanson, A. L., Lyubimova, N., Slatkin, D. N., Stepanek, J. \& Laissue, J. A. (2006). J. Neurooncol. 78, 135143.

Stupp, R., Mason, W. P., van den Bent, M. J., Weller, M., Fisher, B., Taphoorn, M. J., Belanger, K., Brandes, A. A., Marosi, C., Bogdahn, U., Curschmann, J., Janzer, R. C., Ludwin, S. K., Gorlia, T., Allgeier, A., Lacombe, D., Cairncross, J. G., Eisenhauer, E. \& Mirimanoff, R. O. (2005). N. Engl. J. Med. 352, 987-996.

Stupp, R. \& Roila, F. (2008). Ann. Oncol. 19(Suppl. 2), ii83-ii85.

Vredenburgh, J. J., Desjardins, A., Herndon, J. E. II, Dowell, J. M., Reardon, D. A., Quinn, J. A., Rich, J. N., Sathornsumetee, S., Gururangan, S., Wagner, M., Bigner, D. D., Friedman, A. H. \& Friedman, H. S. (2007). Clin. Cancer Res. 13, 1253-1259.

Vredenburgh, J. J., Desjardins, A., Herndon, J. E. II, Marcello, J., Reardon, D. A., Quinn, J. A., Rich, J. N., Sathornsumetee, S., Gururangan, S., Sampson, J., Wagner, M., Bailey, L., Bigner, D. D., Friedman, A. H. \& Friedman, H. S. (2007). J. Clin. Oncol. 25, 4722 4729.

Vulpen, M. van, Kal, H. B., Taphoorn, M. J. \& El-Sharouni, S. Y. (2002). Oncol. Rep. 9, 683-688. 